\title{
O uso do peritônio de paca conservado em solução supersaturada de açúcar a $300 \%$ ou glicerina a $98 \%$ implantados na parede abdominal de ratos
}

[The use of paca peritoneum preserved in supersaturated sugar solution 300\% or glycerine $98 \%$ implanted in the abdominal wall of rats]

\author{
L.M. Leal ${ }^{1}$, A.R.S. Ferreira ${ }^{1}$, A.C.G. Reis ${ }^{2}$, L.L. Martins ${ }^{3}$, S.P. Garcia Filho, R.F. Machado ${ }^{4}$ \\ ${ }^{1}$ Aluno de pós-graduação - Faculdade de Ciências Agrárias e Veterinárias - Unesp - Jaboticabal, SP \\ ${ }^{2}$ Universidade Estadual do Centro-Oeste - UNICENTRO - Guarapuava, SP \\ ${ }^{3}$ Faculdade Ingá - UNINGÁ - Maringá, PR \\ ${ }^{4}$ Faculdade de Ciências Agrárias e Veterinárias - Unesp - Jaboticabal, SP
}

\section{RESUMO}

$\mathrm{Na}$ busca de material biológico alternativo para a realização de implantes, objetivou-se com o presente estudo avaliar comparativamente a implantação do peritônio de paca, uma nova opção de biomaterial, conservado em solução supersaturada de açúcar a 300\% e conservado em glicerina a $98 \%$ na parede abdominal de ratos Wistar. Foram utilizados 60 ratos, machos, da linhagem Wistar, pesando entre 150 e 200 gramas, organizados nos seguintes grupos experimentais: grupo controle (GI), grupo peritônio conservado em solução supersaturada de açúcar a 300\% (GII) e grupo peritônio conservado em glicerina a 98\% (GIII), cada um com 20 animais. Os grupos GII e GIII receberam o enxerto de peritônio da paca conservado em solução de açúcar 300\% e glicerina $98 \%$, respectivamente, e o grupo GI não recebeu a membrana. Cinco ratos de cada grupo foram submetidos à eutanásia em quatro momentos distintos: sete, 15, 30 e 60 dias de pós-operatório para avaliações macroscópicas e microscópicas da interface implante-tecido nativo. Apesar de reações adversas observadas em 57,5\% dos animais do grupo GII e GIII, em 95\% dos animais desses grupos houve boa cicatrização da membrana. Na análise histológica, verificou-se a presença de grande infiltrado inflamatório nos períodos iniciais (sete e 15 dias) e grande presença de tecido conjuntivo nos momentos finais (30 e 60 dias). Concluiu-se que o peritônio da paca como membrana biológica conservado nos meios estudados pode ser utilizado com segurança na parede abdominal de ratos; ainda, que sua conservação em solução supersaturada de açúcar a 300\% permitiu melhor maleabilidade no ato cirúrgico.

Palavras-chave: cicatrização, cirurgia, enxerto, membrana biológica, Cuniculus paca

\begin{abstract}
In the search for alternative biological material to perform implants, this study aimed to compare the implantation of paca peritoneum, a new biomaterial option, preserved in supersaturated sugar solution $300 \%$ and preserved in glycerin $98 \%$ in the abdominal wall of Wistar rats. A total of 60 male rats from the Wistar strain weighing between 150 and 200 grams were housed into three different experimental groups: control group (GI), peritoneum preserved in supersaturated sugar solution $300 \%$ group (GII) and peritoneum preserved in glycerin $98 \%$ group (GIII), with 20 animals each. The GII and GIII received the paca peritoneum graft preserved in sugar solution $300 \%$ and glycerin $98 \%$, respectively and group GI did not receive any membrane. Five rats from each group were euthanized at four different times: seven, 15, 30 and 60 days postsurgery for macroscopic and microscopic evaluations in graft-native tissue interface. Despite the adverse reactions observed in 57.5\% of GII and GIII, there was good healing of the membrane in $95 \%$ of the animals in these groups. Upon histological examination there was a large presence of inflammatory infiltrates in the initial periods (seven and 15 days) and a large presence of connective tissue in the final stages (30 and 60). It was concluded that the paca peritoneum as biological membrane preserved as presented in this study can be used safely in the abdominal wall of rats, the preservation in supersaturated sugar solution $300 \%$ allowed better flexibility during surgery.
\end{abstract}

Keywords: healing, surgery, graft, biological membrane, Cuniculus paca

Recebido em 28 de março de 2013

Aceito em 17 de dezembro de 2013

E-mail: leonardo.vet@hotmail.com 


\section{INTRODUÇÃO}

A reparação cirúrgica ou reforço dos tecidos que compõem a parede da cavidade abdominal é uma das necessidades mais frequentes da cirurgia humana e veterinária (Vulcani et al., 2008).

Muitas vezes não é possível realizar a correção de defeitos na parede abdominal com padrões de suturas convencionais, em virtude tanto da escassez de tecidos quanto da alta tensão na linha de sutura, o que propicia a ocorrência de elevados índices de hérnias incisionais. Em tais casos, torna-se necessário o uso de próteses (Fossum, 2008). Nos animais domésticos, o maior desafio é o desenvolvimento de biomateriais que suportem forças exercidas pelas vísceras em decorrência da posição quadrupedal desses animais, e pela movimentação das estruturas após o procedimento cirúrgico (Vulcani et al., 2008).

Nesse contexto, deve-se considerar o emprego de membranas biológicas, que consistem em implantes de natureza orgânica, livres, inertes e que são aplicadas em locais variados, sendo constituídas, quase exclusivamente, por colágeno, tecido este que lhes confere baixa antigenicidade. Associados a essas características, apresentam ainda baixo custo, facilidade de obtenção e estocagem, esterilização viável e praticidade ao manuseio (Alvarenga, 1992).

O principal objetivo do uso dessas membranas orgânicas, originárias de diferentes espécies animais, ou sintéticas, é fornecer arcabouço para orientação e desenvolvimento de novos tecidos mediante processos de reparação que restabeleçam a estrutura e a função do órgão atingido (Brun et al., 2004).

Dentre as membranas biológicas, o peritônio, aparentemente, não apresenta potencial de transmissão de doenças ao receptor, é facilmente obtido e tem a vantagem de não necessitar de armazenamento especial, sendo conservado em temperatura ambiente por longo período de tempo (Alvarenga, 1992).

$\mathrm{Na}$ procura, tanto de material biológico alternativo para a realização de implantes quanto de novas opções de modelos de experimentação animal, surge a paca (Cuniculus paca, Linnaeus 1766), uma espécie pertencente à ordem dos roedores, típica de regiões tropicais (Redford e Robinson, 1991), presente em grande parte do território brasileiro e
América Latina (Queirolo et al., 2008). Essa espécie alimenta-se de frutas, mas pode consumir outros vegetais e até insetos em períodos de escassez alimentar (Dubost e Henry, 2006). Em cativeiro, pode atingir $80 \mathrm{~cm}$ de comprimento, $12 \mathrm{~kg}$ de massa corpórea e 16 anos de tempo médio de sobrevida (Queirolo et al., 2008). Sua importância, além da comercial como fonte proteica, pode também tomar âmbito da ciência, pois a paca apresenta características como: tamanho adequado, ampla distribuição geográfica, adaptação a ambientes variados, nutrição variada, entre outras, que atendem às condições atribuídas a modelo animal experimental (Santos, 2006).

Assim, dado o crescente uso de materiais biológicos em cirurgias reconstrutivas e a constante busca por métodos de conservação para os diversos tecidos (Mota et al., 2002), objetivou-se comparar o peritônio da paca conservado em solução supersaturada de açúcar a $300 \%$ ou em glicerina a 98\% quando implantadas na parede abdominal de ratos no que se refere à biocompatibilidade, capacidade de cicatrização e possíveis complicações, mediante realização de análises clínicas, macroscópicas e histológicas.

\section{MATERIAL E MÉTODOS}

A presente metodologia foi aprovada pela Comissão de Ética no Uso de Animais (CEUA) da Faculdade de Ciências Agrárias e Veterinárias (FCAV-UNESP), Jaboticabal-SP, de acordo com o Colégio Brasileiro de Experimentação Animal (COBEA) sob o número de protocolo 012730/11.

Foram utilizados 60 ratos, machos, da linhagem Wistar, pesando entre 150 e 200 gramas. Os animais foram mantidos em gaiolas individuais de $30 \mathrm{~cm} \times 20 \mathrm{~cm} \times 18 \mathrm{~cm}$, localizadas no Biotério do Departamento de Morfologia e Fisiologia Animal da FCAV, Unesp, Campus de Jaboticabal, e receberam ração e água à vontade.

Os animais foram divididos, de acordo com os tratamentos, em três grupos experimentais: GI grupo controle $(n=20)$, GII - grupo peritônio conservado em solução supersaturada de açúcar de cana-de-açúcar a $300 \%(\mathrm{n}=20)$ e GIII - grupo peritônio conservado em glicerina a $98 \% \quad(n=20)$. Destes, dividiu-se cada grupo em quatro subgrupos $(\mathrm{n}=5)$, referentes ao momento da eutanásia, para avaliações macroscópicas e microscópicas: M7 aos 7 dias, M15 - aos 15 dias, M30 - aos 30 dias, M60 - aos 60 dias de pós-operatório. 
As pacas utilizadas no experimento foram provenientes do plantel de pacas do setor de Animais Silvestres da FCAV, Unesp, que é registrado no Instituto Brasileiro do Meio Ambiente e dos Recursos Naturais Renováveis - IBAMA como criatório de espécimes da fauna brasileira para fins científicos (cadastro de registro - 482508).

A eutanásia das pacas foi realizada mediante sedação prévia com meperidina $(3 \mathrm{mg} / \mathrm{kg})$ associada a midazolan $(1 \mathrm{mg} / \mathrm{kg})$, pela via intramuscular, anestesia geral com quetamina $(25 \mathrm{mg} / \mathrm{kg})$ e xilazina $(0,5 \mathrm{mg} / \mathrm{kg})$, também pela via intramuscular, e, por fim, injeção intravenosa de cloreto de potássio $19,1 \%$, dose-efeito, até a parada cardiorrespiratória. Assim, logo após a eutanásia, realizava-se a colheita do peritônio parietal, o qual era lavado em solução fisiológica $\mathrm{NaCl}$ 0,9\% para retirada de sujidades, sangue e tecidos que ficaram aderidos. Posteriormente, os seguimentos peritoniais, direito e esquerdo, foram divididos em duas porções e cada uma delas foi acondicionada em frasco de vidro estéril distinto, um contendo a solução supersaturada de açúcar a $300 \%$ e o outro contendo solução de glicerina a $98 \%$. Os segmentos de membrana permaneceram totalmente imersos para conservação e armazenamento, sob temperatura ambiente, por período não inferior a 30 dias.

Para a preparação da solução supersaturada de açúcar a $300 \%$, segundo metodologia empregada por Mazzanti et al. (2001), utilizou-se 300 gramas de açúcar cristalizado em 100 mililitros de água destilada, obtendo-se no final uma solução na proporção 3:1. Após 48 horas de imersão, a membrana foi colocada em nova solução de açúcar a $300 \%$, pois sua desidratação promove a diluição da solução inicial.

Nos ratos do grupo controle, sob anestesia geral na dose de $50 \mathrm{mg} / \mathrm{kg}$ de quetamina associada a $20 \mathrm{mg} / \mathrm{kg}$ xilazina, administrada pela via intramuscular, realizou-se incisão abdominal mediana, estendendo-se da região xifoide à púbica, e retirou-se um segmento elíptico da musculatura abdominal com suas aponeuroses, medindo $2 \mathrm{~cm}$ de comprimento por $1 \mathrm{~cm}$ de largura; em seguida realizou-se a rafia muscular com sutura simples contínua com fio de náilon 4-0. A redução do tecido subcutâneo foi realizada em zigue-zague e a sutura de pele em "U”' (Wolff), ambos com náilon 4-0.

Nos animais dos grupos GII e GIII, retirou-se um segmento de $2 \times 2 \mathrm{~cm}$ da musculatura abdominal, da mesma região feita no grupo controle, promoveu-se sua substituição com um fragmento, do mesmo tamanho, de membrana de peritônio da paca, suturada com fio de náilon 4-0 de forma simples contínua (Fig. 1). Segundo a metodologia empregada por Daleck et al. (1988), os fragmentos de peritônio foram removidos dos frascos 15 minutos antes de sua implantação, lavados abundantemente com solução físiológica de $\mathrm{NaCl}$ $0,9 \%$ e imersos numa cuba estéril contendo a solução salina à temperatura ambiente para reidratação. A redução do tecido subcutâneo e a sutura de pele foram realizadas como no grupo controle.

Diariamente, até o momento da eutanásia, os animais eram avaliados clinicamente à procura de possíveis alterações no aspecto da ferida cirúrgica. Para as avaliações macroscópicas e microscópicas, os ratos foram eutanasiados nos diferentes momentos (M7, M15, M30 e M60) mediante a administração de $100 \mathrm{mg} / \mathrm{kg}$ de quetamina associada com $20 \mathrm{mg} / \mathrm{kg}$ de xilazina, por via intramuscular, seguida por deslocamento cervical, toracotomia e perfusão intracardíaca em bomba com velocidade de $8 \mathrm{~mL} /$ minuto, primeiramente com uma solução heparinizada a $2 \%$ em tampão fosfato $0.1 \mathrm{M}$ ph 7.4, e posteriormente fixada com solução Karnovsky modificado (glutaraldeído 3\% e paraformol 1\% em Tampão fosfato $0.1 \mathrm{M}$ ph 7.4).

Foram removidos fragmentos com $9 \mathrm{~cm}^{2}(3 \times 3 \mathrm{~cm}) \mathrm{da}$ interface implante/tecido nativo de todos os animais. Esses fragmentos foram acondicionados em frascos universais com solução Karnovsky modificada (glutaraldeído 3\% e paraformol 1\% em tampão fosfato $0.1 \mathrm{M}$ ph 7.4) para fixação. $\mathrm{O}$ material para a análise histopatológica foi incluído em Paraplast (Behmer et al., 1976). A microtomia foi realizada em micrótomo automático (RM 2155, Leica-Germany), obtendo-se cortes de $5 \mu \mathrm{m}$, que foram fixados em lâminas e submetidos às colorações por Hematoxilina e Eosina (HE). Todas as preparações foram fotodocumentadas em microscópio de luz (DM 5000 B, Leica-Germany) para análise morfológica.

A relação de dependência (associação) entre os grupos e as variáveis observadas (boa cicatrização, presença de fístula cutânea, expulsão da membrana, evisceração, aderência, seroma e abscesso) na avaliação macroscópica foi efetuada pelo teste exato de Fisher, adotando-se o nível de significância de 5\% por meio do software SAS 9.1 (SAS Institute-USA). 


\section{RESULTADOS E DISCUSSÃO}

No grupo controle (GI), clinicamente, todos os animais apresentaram boa cicatrização da ferida cirúrgica e ausência de reações teciduais adversas, o que corrobora as descrições de Turner e McIlwraith (1985) ao afirmarem que o náilon é um fio relativamente inerte que causa mínima reação tecidual.

Durante a colheita do peritônio da paca, observouse que este possuía, macroscopicamente, uma maior ou menor quantidade de tecido adiposo de acordo com sua localização. Na região mais ventral, próximo à linha Alba, o peritônio era mais delgado e livre de tecido adiposo; na região mais dorsal, próximo à coluna vertebral, era espesso com grande quantidade de tecido gorduroso. No ato cirúrgico, utilizou-se aleatoriamente nos animais um peritônio delgado ou espesso.

Segundo Alvarenga (1992), as membranas biológicas devem ser inertes, com predominância de material rico em colágeno e isento de tecido muscular e adiposo. Assim, o aumento de volume abdominal seguido por fistulação cutânea que foi observado na avaliação clínica do $12^{\circ}$ dia de pósoperatório em $50 \%$ e $65 \%$, respectivamente (Fig. 2), dos animais do GII e GIII, além da expulsão da membrana, verificada em 5\% dos ratos do GIII, e a evisceração intestinal, notada em $5 \%$ dos animais também no GIII, provavelmente decorreram de uma reação tecidual provocada pela grande quantidade de tecido adiposo existente em parte do peritônio da paca que foi implantado.

Reforça-se a ideia de que o tecido adiposo favorece a rejeição do enxerto pelo hospedeiro (Alvarenga, 1992), pois, em $100 \%$ dos animais que receberam o peritônio com pouca quantidade de tecido gorduroso, correspondendo a $50 \%$ e $35 \%$ dos animais do grupo GII e GIII, respectivamente, houve, clinicamente, boa cicatrização da ferida cirúrgica e ausência de reações teciduais adversas, tal qual ocorreu no grupo controle.

Dessa forma, recomenda-se que a colheita do peritônio da paca, para o uso em enxertos como membrana biológica, seja da região mais ventral do abdômen, próxima à linha Alba, onde a membrana é mais delgada e livre de tecido gorduroso. $\mathrm{Na}$ avaliação macroscópica e microscópica do peritônio da paca, Camargo et al. (2012) verificaram a presença de tecido adiposo nessa membrana, todavia não quantificaram esse tecido.
Atribui-se a boa cicatrização da ferida cirúrgica e a ocorrência de pequena aderência do omento à linha de sutura abdominal, observada em todos os animais do grupo controle em todos os momentos (M7, M15, M30 e M60), à pouca reação tecidual provocada pelo náilon (Turner e McIlwraith, 1985; Rahal et al., 1997; Boothe, 2007).

No GII e no GIII, foi verificada boa cicatrização do peritônio de paca à musculatura abdominal em $95 \%$ dos animais, como também observada no uso do pericárdio canino (Brun et al., 2002), do pericárdio bovino (Quitzan et al., 2003) e do peritônio bovino (Bastos et al., 2005), quando implantados na parede abdominal de ratos.

A aderência acentuada do omento, ora observada nos animais que receberam a membrana, é fato comum no uso de membranas biológicas e também foi verificada no emprego de retalho de peritônio bovino na substituição a segmento diafragmático em cães (Daleck et al., 1988); no uso de peritônio autólogo em cistoplastia de cães (Daleck et al., 1989); no estudo do pericárdio canino e bovino na reparação do músculo reto abdominal de ratos (Brun et al., 2002; Quitzan et al, 2003); na cistoplastia experimental em coelhos utilizando o peritônio bovino (Oliveira et al., 2008); e na hernioplastia experimental em coelhos por meio de cartilagem auricular bovina (Silva et al., 2009).

Verificou-se aumento de volume da membrana com conteúdo seroso não purulento em um animal do GII, no M15, e em todos os animais do GIII, no M7; observou-se ainda a presença de fístula não infeccionada com conteúdo seroso em um animal do GII, no M7. Todos esses animais receberam o peritônio com grande quantidade de tecido adiposo. Dessa forma, reforçam-se as observações de Alvarenga (1992), ao afirmar que as membranas biológicas devem ser livres de tecido adiposo.

Abscesso foi verificado em $40 \%$ dos animais do GIII no M15, em 20\% dos animais do GII no M30 e em 20\% dos animais do GIII, também no M30 (Fig. 3). Essa reação adversa ocorreu sempre após fistulação cutânea inicial observada na avaliação clinica. Acredita-se que o contato direto da ferida cirúrgica com as fezes do próprio animal favoreceu a contaminação da fístula e posterior formação do abscesso. Tal ocorrência corrobora, em parte, as descrições de Daleck et al. (1992) que, ao estudarem o uso do peritônio bovino na reparação de hérnia perineal em cães, relataram que a contaminação da ferida cirúrgica com as fezes do animal levou à rejeição do implante. Todavia, no 
presente estudo, a infecção não provocou a expulsão da membrana.

Há décadas, as contaminações de membranas biológicas, dos instrumentos e do centro cirúrgico são referidas como as principais causas de infecção e rejeição do enxerto (Pigossi et al., 1964; Alvarenga, 1992; Brun et al., 2002; Oliveira et al., 2009). Entretanto, neste estudo, o abscesso verificado em alguns animais teve sua origem póscirúrgica, pois apenas os animais que apresentaram a fistulação da pele desenvolveram a infecção; no grupo controle e nos animais que receberam o peritônio livre de gordura, não se verificou fistulação cutânea e consequente formação de abscesso. Assim, reforça-se a ideia de que a presença de abscesso foi em decorrência da contaminação da fístula pelos dejetos do próprio animal, e não por contaminação da membrana ou dos instrumentos.

Verificou-se em $100 \%$ dos animais do GII e GIII, no M60, mudança na forma do enxerto e difícil delimitação de sua margem com consequente dificuldade na identificação da membrana (Fig. 4), o que corrobora os estudos de Pigossi (1964) na implantação de dura-máter homógena em cães, de Daleck et al. (1988) na substituição de um retalho diafragmático em cão por peritônio bovino, e de Brun et al. (2002) na utilização do pericárdio canino no reparo do músculo reto abdominal de ratos, os quais afirmam que as membranas fornecem arcabouço para orientação e desenvolvimento de novos tecidos, possibilitando sua incorporação ao organismo receptor mediante processos de reparação que restabelecem a estrutura ou a função do órgão atingido.

Quanto aos meios de conservação da membrana avaliados neste estudo, estatisticamente verificou-se que estes não interferiram nos resultados clínicos e macroscópicos observados, pois os grupos GII e GIII tiveram a mesma resposta clínica em relação ao processo cicatricial e biocompatibilidade no uso do peritônio da paca em todo o período pósoperatório, bem como na avaliação macroscópica nos diferentes momentos de eutanásia (Fig. 5). Tal ocorrência corrobora as observações de Gonçalves et al. (2003) ao afirmarem que a solução de açúcar a $300 \%$ e a glicerina a $98 \%$ proporcionaram resultados clínicos semelhantes e satisfatórios na conservação de córneas para ceratoplastias em cães.
Comparando-se isoladamente cada grupo que recebeu a membrana (GII e GIII) com o grupo controle (GI), estatisticamente, houve diferença significativa apenas quanto à presença de seroma $\mathrm{e}$ fistula cutânea; todavia, os grupos GII e GIII foram iguais entre si em todos os parâmetros observados (Fig. 5).

Presenciou-se ainda que as membranas conservadas em solução de açúcar a $300 \%$ apresentaram melhor maleabilidade no ato cirúrgico, assemelhando-se ao peritônio a fresco, ao passo que o material conservado em glicerina, mesmo após a reidratação, mantinha-se mais rígido. Tais observações contrariam as descrições de Bastos et al. (2005), na aplicação de peritônio bovino, conservado em glicerina a $98 \%$, em hérnia ventral de ratos, ao relatarem a manutenção da maleabilidade da membrana mesmo antes do período de reidratação. Segundo Alvarenga (1992), a menor maleabilidade da membrana no ato cirúrgico dificulta sua implantação em diferentes tecidos.

Histologicamente, verificou-se em todos os momentos de avaliação do GI a presença de fina camada de tecido fibroso ao redor do fio de sutura separando as camadas musculares, além de pouco infiltrado inflamatório, o que apoia as observações de Turner e McIlwraith (1985) e Boothe (2007), ao afirmarem que o náilon provoca discreta reação tissular.

A ocorrência de infiltrado inflamatório com predominância de mononucleares verificada no GI, em todos os momentos (M7, M15, M30 e M60), também foi observada por Rahal et al. (1997) na utilização do fio de náilon cirúrgico e "linha de pesca esterelizada" na parede abdominal de ratos.

Constatou-se a presença de células mononucleares no GII e GIII em todos os momentos estudados, fato este também verificado por Brun et al. (2002) no uso do pericárdio canino conservado em solução supersaturada de sal implantado na parede abdominal de ratos wistar. Neste estudo, os autores notaram maior concentração de mononucleares nos tempos iniciais, com diminuição progressiva até o último período de avaliação. Tais autores relatam ainda que a resposta inflamatória por células polimorfonucleares foi abundante no período de três dias após o procedimento cirúrgico; entretanto, esse momento não foi avaliado no estudo em questão; assim, raras células polimorfonucleares foram verificadas nessa oportunidade. 

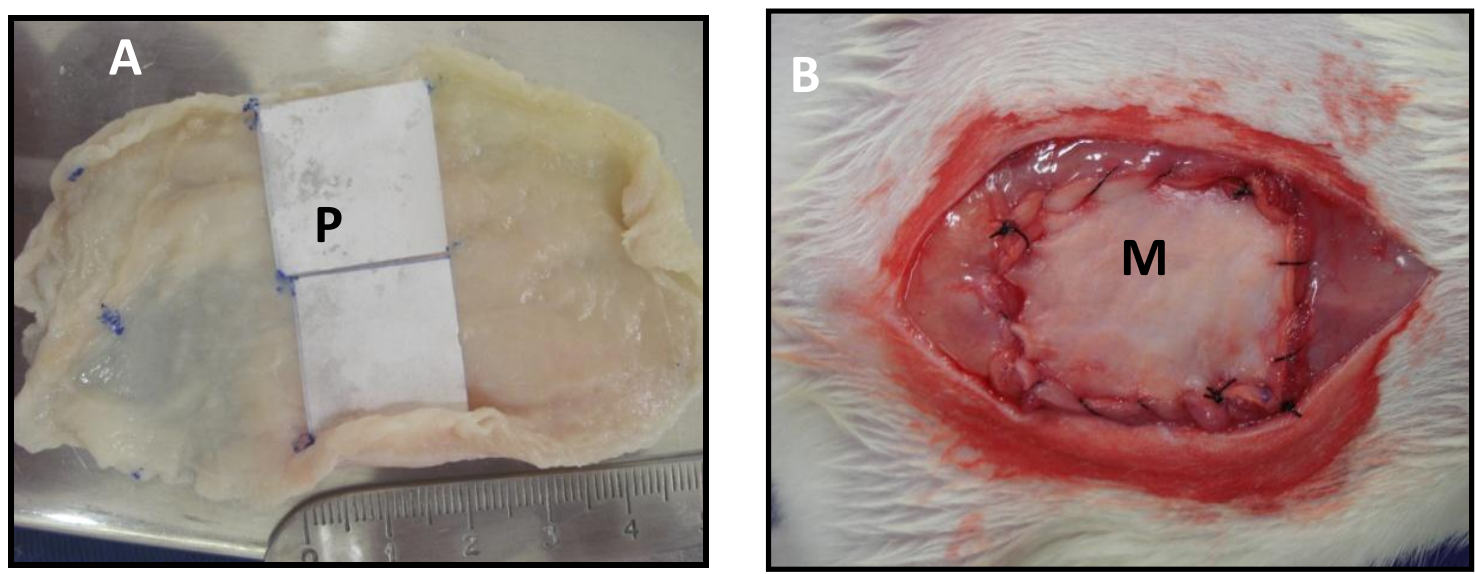

Figura 1. Imagens fotográficas. Em A nota-se a demarcação do segmento de peritônio abdominal medindo $2 \mathrm{~cm} \times 2 \mathrm{~cm}(\mathrm{P})$ e em B nota-se a membrana suturada com fio de náilon 4-0 em um rato Wistar macho do GII (M).

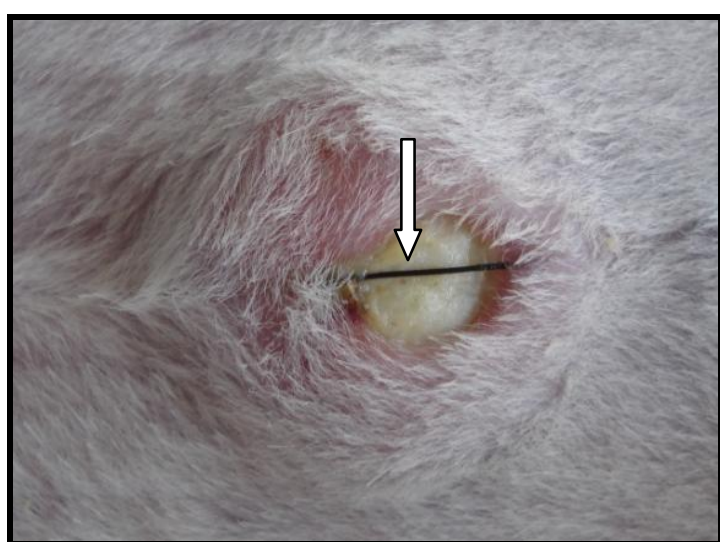

Figura 2. Imagem fotográfica de um rato Wistar pertencente ao GIII. Nota-se fistulação na pele aos 12 dias de pós-operatório (seta).

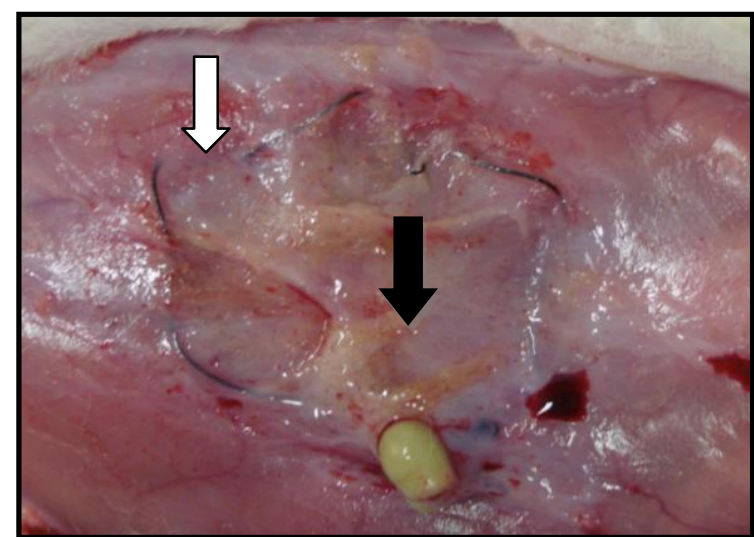

Figura 3. Imagem fotográfica do abdômen de rato Wistar, macho, pertencente ao GII, no M30, no qual se nota presença de abscesso na área do implante (seta preta), embora haja boa cicatrização da membrana com a musculatura (seta branca).

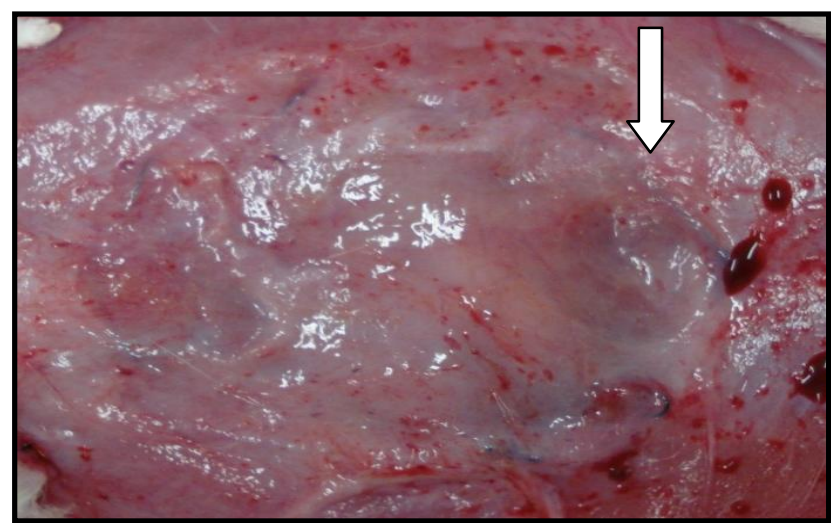

Figura 4. Imagem fotográfica do abdômen de um rato Wistar, macho, pertencente ao GIII, eutanasiado aos 60 dias de pós-operatório. Nota-se a dificuldade em delimitar as margens da membrana com a musculatura (seta). 


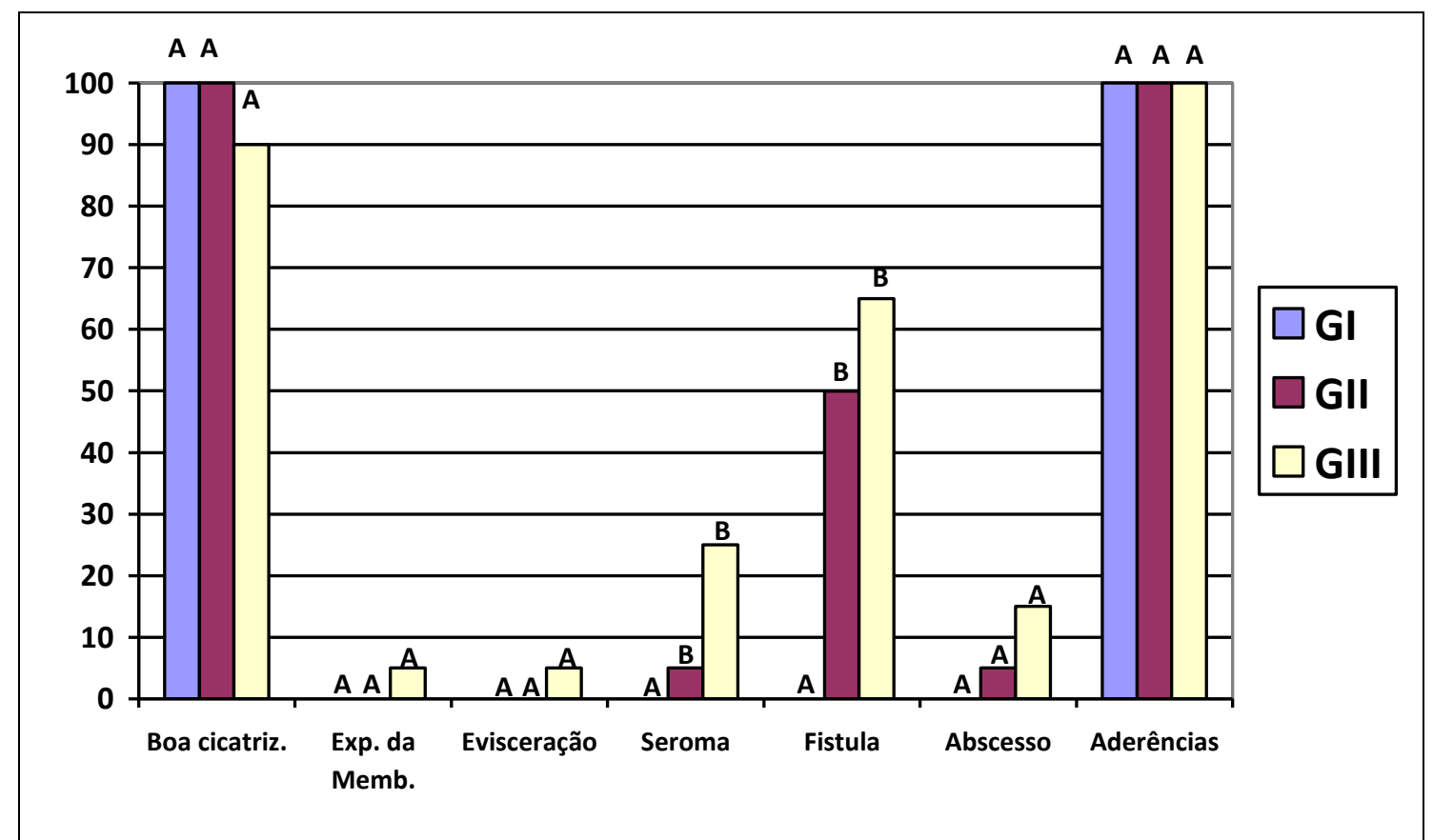

Figura 5. Gráfico dos resultados observados na análise macroscópica (boa cicatrização, expulsão da membrana, evisceração, seroma, fístula cutânea, abscesso e aderências) dos animais em todos os grupos, expressos em porcentagem, sem considerar o momento de avaliação. Os grupos seguidos pelas mesmas letras em cada observação não diferem entre si pelo teste de Fisher a 5\% de significância.

Nos animais do GII e GIII que receberam o peritônio da paca, ficou demonstrada a ocorrência de reação inflamatória aguda (M7 e M15), que gradativamente foi desaparecendo, e a membrana foi sendo substituída por tecido conjuntivo fibroso entremeado ao tecido muscular (M30 e M60) (Fig. 6). Tal padrão de resposta foi evidenciado em estudos referentes a diferentes materiais biológicos conservados, tanto na glicerina quanto na solução supersaturada de açúcar (Pigossi, 1964; Daleck et al., 1987; Daleck et al., 1988; Mazzanti et al., 2001). Sabe-se que as membranas biológicas atuam como arcabouço para o crescimento do tecido vivo (Alvarenga, 1992) e, dessa forma, o peritônio da paca também teve essa atuação, independentemente dos meios em que foram conservados.

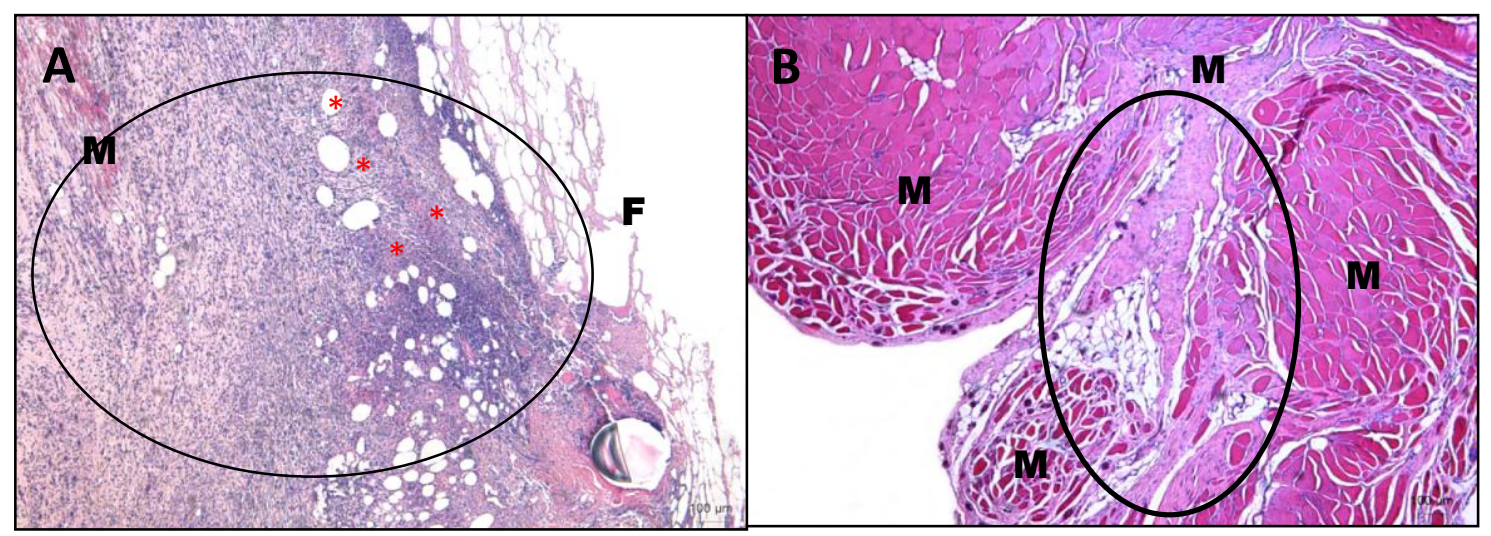

Figura 6. Fotomicrografias da região de implante de peritônio da paca em ratos Wistar, machos, GII. Em A, M7, nota-se área de fibrose (elipse) com grande infiltrado inflamatório próximo ao fio de sutura (F), separado do tecido muscular $(\mathrm{M})$, e imagem negativa de tecido adiposo (*). Em B, M60, verifica-se, no local onde o implante foi afixado, a presença de tecido fibroso (elipse) entremeado ao tecido muscular (M) com poucas células inflamatórias (Paraplast, HE, 5X). 


\section{CONCLUSÃO}

Da forma que se conduziu este experimento e mediante os resultados observados nas avaliações macroscópicas e histológicas, pode-se concluir que o peritônio de paca como membrana biológica conservado nos meios estudados pode ser utilizado com bons resultados referentes à biocompatibilidade e capacidade de cicatrização na parede abdominal de ratos, especialmente quando colhido da parede abdominal mais ventral da paca. Conclui-se também que, embora a cicatrização e reações adversas tenham sido, estatisticamente, semelhantes nos grupos GII e GIII, a conservação da membrana em solução supersaturada de açúcar a $300 \%$ permitiu melhor maleabilidade no ato cirúrgico quando comparada à conservação em glicerina a $98 \%$.

\section{AGRADECIMENTOS}

À Fundação de Amparo à Pesquisa do Estado de São Paulo (FAPESP), sinceros agradecimentos pelo financiamento do estudo em questão.

\section{REFERÊNCIAS}

ALVARENGA, J. Possibilidades e limitações da utilização de membranas biológicas preservadas em cirurgia. In: DALECK, C.R.; BAPTISTA, L.C.; MUKAI, L.S. (Eds). Tópicos em cirurgia de cães $e$ gatos. Jaboticabal: FUNEP-UNESP, 1992. p.33-42.

BASTOS, E.L.S.; FAGUNDES, D.J.; TAHA, M.O. et al. Peritônio bovino conservado na correção de hérnia ventral em ratos: uma alternativa para tela cirúrgica biológica. Rev. Col. Bras. Cir., v.32, p.256-260, 2005.

BEHMER, A.O.; TOLOSA, E.M.C.; FREITASNETO, A.G. Manual de técnicas para histologia normal e patológica. São Paulo: EDART, 1976. 239p.

BOOTHE, H.W. Fios de sutura, adesivos de tecidos, grampeadores e clipes hemostáticos. In: SLATTER, D. (Ed). Manual de Cirurgia de Pequenos Animais. Barueri: MANOLE, 2007. p.235-243.

BRUN, M.V.; PIPPI, N.L.; DREIMEIER, D. et al. Solução hiperstaurada de sal como conservante de pericárdio canino utilizado na reparação do músculo reto abdominal de ratos Wistar. Cienc. Rural, v.32, p.1019-1025, 2002.

BRUN, M.V.; PIPPI, N.L.; DREIMEIER, D. et al. Solução hipersaturada de sal ou de glicerina a $98 \%$ como conservantes de centros frênicos caninos utilizados na reparação de defeitos musculares em ratos wistar. Cienc. Rural, v.34, p.147-153, 2004.
CAMARGO, A.D.; LEAL, L.M.; GARCIA FILHO, S.P. et al. Propriedades morfológicas do peritônio da paca (Cuniculus paca, L. 1766) a fresco e conservados em glicerina 98\%. Biotemas, v.25, p.187-194, 2012.

DALECK C.R.; ALESSI A.C.; COSTA-NETO, J.M. et al. Substituição de um retalho diafragmático de cão por peritônio de bovino conservado em glicerina: estudo experimental. Ars Vet., v.4, p.53-61, 1988.

DALECK, C.R.; DALECK, C.L.M.; FILHO, J.G. P.; NETO, J.C.M. Reparação de hérnia perineal em cães com peritônio de bovino conservado em glicerina. Cienc. Rural, v.22, p.179-183, 1992.

DALECK, C.L.M.; DALECK, C.R.; PADILHAFILHO, J.G. Cistoplastia com pertiônio autólogo em cães. Semina, v.10, p.22-26, 1989.

DUBOST, G.; HENRY, O. Comparison of diets of the acouchy, agouti and paca, the three largest terrestrial rodents of French Guianan forests. J. Trop. Ecol., v.22, p.641-651, 2006.

FOSSUM, T.W. Cirurgia da Cavidade Abdominal. In:_ (Ed).. Cirurgia de pequenos animais. Rio de Janeiro: ELSEVIER, 2008. p.317-338.

GONÇALVES, G.F.; PIPPI, N.L.; RAISE, A.G. et al. Ceratoplastia lamelar homóloga em cão com conservação supersaturada de açúcar ou glicerina aspectos macroscópicos. Arq. Cienc. Vet. Zool., v.6, p.31-37, 2003.

MAZZANTI, A.; PIPPI, N.L.; RAISER, A.G. et al. Músculo diafragma homólogo conservado em solução supersaturada de açúcar para a reparação de grande defeito na diafragma de cão. Cienc. Rural, v.31, p.277-283, 2001.

MOTA, F.C.D.; EURIDES, D.; FREITAS, P.M.C. et al. Análise morfológica e microbiológica utilizando-se diferentes métodos de preservação sobre a camada muscular do intestino delgado de cães. Cienc. Anim. Bras., v.4, p.117-123, 2003

OLIVEIRA, L.L.; SOUZA, D.B.; ABÍLIO, E.J.; CARVALHO, E.C. Métodos de preservação de membranas biológicas para uso cirúrgico. JBCA, v.2, p.175-188, 2009

OLIVEIRA, T.C.; SCAVONE, A.R.F.; MACHADO, M.R.F.; MAZZUCATTO, B.C. Cistoplastia experimental em coelhos (Oryctolagus cuniculus) com peritônio bovino conservado em glicerol a $98 \%$. Cienc. Rural, v.38, p.2218-2224, 2008. 
PIGOSSI, N. Implantação de dura-máter homógena conservada em glicerina-estudo experimental em cães. 1964. 41f. Tese (Doutorado em Medicina). Faculdade de Medicina, Universidade de São Paulo, São Paulo.

QUEIROLO, D.; VIEIRA, E.; EMMONS, L.; SAMUDIO, R. Cuniculus paca. In: IUCN Red List of Threatened Species, Version 2010.1, 2008. Disponível em:<www.iucnredlist.org>. Acessado: 28 mar. 2010.

QUITZAN, G.Q.; RAHAL, S.C.; ROCHA, N.S.; CROCCI, A.J. Comparação entre pericárdio bovino preservado em glicerina e malha de poliéster no reparo de falhas da parede abdominal em ratos. Acta Cir. Bras, v.18, p.297-301, 2003.

RAHAL, S.C.; ROCHA, N.S.; FIGUEIREDO, L.A.; IAMAGUTI, P. Estudo comparativo das reações teciduais produzidas pela "linha de pesca" (poliamida) e fio de náilon cirúrgico. Cienc. Rural, v.28, p.89-93, 1997.

REDFORD, K.H.; ROBINSON, J.G. Subsistence and commercial uses of wildlife in Latin America. In: (Eds). Neotropical wildlife use and conservation. Chicago: THE UNIVERSITY OF CHICAGO PRESS, 1991. p.6-23.
SANTOS, B.F. Modelo Animal. In: ANDRADE, A.; PINTO, S.C.; OLIVEIRA, R.S. Animais de laboratório: criação e experimentação. Rio de Janeiro: FIOCRUZ, 2006. p.23-24.

SILVA, L.A.F.; FRANCO, L.G.; MENEZES, L.B. et al. Hernioplastia experimental em coelhos por meio de cartilagem auricular bovina conservada em glutaraldeído. Arq. Bras. Med. Vet. Zootec, v.61, p.606-612, 2009.

TURNER, A.S.; McILWRAITH, C.W. Materiais de sutura e agulhas. In (Eds). Técnicas cirúrgicas em animais de grande porte. São Paulo: ROCA, 1985. p.67-77.

VULCANI, V.A.S.; MARCORIS, D.G.; PLEPIS, A.M.G. et al. Obtenção, caracterização e aplicação cirúrgica de matrizes de colágeno na parede abdominal de eqüinos. Cienc. Anim. Bras, v.9, p.778-785, 2008. 